\title{
An Experimental Study on the Geotechnical, Mineralogical, and Swelling Behavior of KPK Expansive Soils
}

\author{
Bakht Zamin (D), ${ }^{1}$ Hassan Nasir, ${ }^{2}$ Khalid Mehmood, ${ }^{3}$ Qaiser Iqbal $\left(\mathbb{D},{ }^{3}\right.$ Asim Farooq (D), \\ and Mohammad Tufail ${ }^{5}$ \\ ${ }^{1}$ Civil Engineering Department, CECOS University of IT \& Emerging Sciences, Peshawar, Pakistan \\ ${ }^{2}$ Water and Sanitation Services (WSSP), Peshawar, Pakistan \\ ${ }^{3}$ Civil Engineering Department, Sarhad University of Science \& Information Technology (SUIT), Peshawar, Pakistan \\ ${ }^{4}$ Pak-Austria Fachhochschule: Institute of Applied Sciences \& Technology, (PAF-IAST), Haripur, Pakistan \\ ${ }^{5}$ Consulting Engineer, Islamabad, Pakistan \\ Correspondence should be addressed to Bakht Zamin; bakhtzamin82@gmail.com
}

Received 28 April 2021; Revised 21 June 2021; Accepted 25 June 2021; Published 8 July 2021

Academic Editor: Paolo Castaldo

Copyright ( $) 2021$ Bakht Zamin et al. This is an open access article distributed under the Creative Commons Attribution License, which permits unrestricted use, distribution, and reproduction in any medium, provided the original work is properly cited.

\begin{abstract}
Expansive soils are found in numerous regions of the world explicitly in arid and semiarid zones. These soils expand when absorbed moisture and shrink when released water. Such soil is viewed as a characteristic risk for infrastructures due to the shrink and swell behavior. These soils become more problematic when lightly or moderately loaded structures are built on them. The swelling and shrinkage in these soils chiefly happen due to the presence of montmorillonite minerals. The mineralogical and swell behavior of foundation soils is playing a vital role in the overall stability of a structure. These parameters are often ignored in the geotechnical report writing stage specifically in small projects, due to which, the durability and service life of the facilities are reduced and the maintenance cost is increased. To mitigate the potential damages in structures constructed on expansive soil, it is necessary to assess the mineralogical and swelling characteristics of expansive soil. The current study aims to determine the geotechnical, mineralogical, and swell behavior of the local expansive soils. Based on the results, the Karak soil has the highest plasticity index (PI) of $37 \%$ with a clay fraction of $28 \%$, while the D.I. Khan soil has the least PI of $23 \%$ with a clay fraction of $17 \%$. Similarly, Karak's soil contained a higher percentage of montmorillonite $(\mathrm{Rp}=8.9 \%)$. The maximum values of swell pressure, swell potential, and $1 \mathrm{D}$ deformation are $280 \mathrm{kPa}, 12.5 \%$, and $1.92 \mathrm{~mm}$ for the Karak soil, $6.45 \% 150 \mathrm{kPa}$, and $1.38 \mathrm{~mm}$ for D.I. Khan soil, and $10.5 \%, 245 \mathrm{kPa}$, and $1.64 \mathrm{~mm}$ for Kohat soil, respectively. This concludes that Karak's soil has high plasticity and swell characteristics than Kohat and D.I. Khan soil. The swell characteristic of expansive soils increases with the increase in the percentage of the fine specifically the clay fraction. Furthermore, the Karak soil is more critical than Kohat and D.I. khan soil for lightly loaded structures.
\end{abstract}

\section{Introduction}

Expansive soil is a typical soil that goes through enormous volume changes after changing the water content. The volume changes in such soils can be developed as an expansion or as a shrinkage. This soil swells and shows an increment in the volume when its water content is increased, while volume is reduced considerably upon the reduction in their moisture content. Expansion is initiated from the partial saturation condition and continued until the full saturation. Expansive soil is so sensitive to moisture that a slight increase (1 2\%) in moisture can cause detrimental swelling. If swelling is prevented, it exerts swelling pressure and lifts or heaves the structure, while shrinkage may cause differential settlement. Additionally, the swell-shrink behavior is more pronounced in the surficial zone and very rare in deep layers of the soil as moisture fluctuation is more critical in the top few meters' depths. Hence, shallow foundations are more susceptible to distress when constructed on expansive soils. In dry conditions, differential 
settlement often occurs in lightweight structures while swell pressure is exerted on the foundation in case of confined saturated conditions.

Desiccation cracks are produced on the surface of such soil when their moisture is reduced naturally by evaporation or by some artificial process. Generally, expansive soils have moderate to high plastic index and high variability in bearing capacity and strength depending on the moisture condition [1]. Expansive soil is clayey and found in arid and semiarid climatic conditions. Clayey-type minerals are predominate in swelling soil microstructure, generating these soils to absorb moisture between their layers and then undergo volume changes [2]. If clayey minerals belong to montmorillonite from the smectite class or some kind of illite, then it will have remarkable swelling latency after the addition of water. Clay minerals in these soils spring up from the chemical alteration of limestone, shale, sandstone, and slate. Another point source is the alteration of volcanic residue accumulated in the marine environment after the geological period and settled separately or heterogeneous with shale or limestone [3]. Semitropical climate affects the constitution of this clayey soil and speeds up the extraction and weathering processes of the parent rock.

1.1. Presence of Expansive Soils. The presence of swelling soils has been noticed worldwide in many states and regions including Australia, China, Canada, India, North Africa, Egypt Israel, Iran, Turkey, Mexico, the USA, and many other underdeveloped countries, where the related problems have not yet explored $[4,5]$. As some places of Pakistan also exist in the semiarid topographic points, expansive soil of medium to high plasticity exists abundantly in these regions. Swelling clays are present in many districts of Khyber Pakhtunkhwa (KPK), Pakistan like Bunnu, Kohat, Charassada, Karak, Nowshera, Dera Gazi (D.G.) Khan, Dera Ismail (D.I.) Khan, and so many other places as well [6] and have damaged many structures.

1.2. Associated Problems and Mechanism. Expansive soils are considered potential natural hazards causing serious damage and distortion to infrastructure if not adequately treated. This deformation can be the worst in severe conditions, i.e., flood or drought. The expansive soils have made exceptional distress in civil engineering structures, specifically to lightly loaded structures, for example, buildings, pavements, canal linings, etc. The problems associated with foundations on expansive soils incorporate heaving, breaking, and cracking of the superstructure. It also produces distress in pavements, slab-on-grade members, channels, and reservoir linings [6]. The adversity of swelling soils to lightweight structures is more substantial because of large swelling pressure. The structure like boundary walls, one to three-storied houses, pavements, pathways, highways, underground facilities of water, etc., is subjected to severe distress when placed over or under expansive soil. The swelling mechanism is very complex and speculative; swelling pressure often approaches to uplift the foundation of lightweight structures and pavements, provoking partial damage or complete demolition subsequent monetary financial losses [7-9].

It is worth mentioning that the estimated expenditure of damage to the civil engineering structures due to the presence of expansive soils is greater than any other natural disaster like flood, hurricane, earthquake, and tornadoes. In the United States alone, the expenditure of damages originates due to the presence of expansive soil amounts to 2.3 billion dollars every year [10]. In Jordan, more than $40 \%$ of structures were gravely damaged by the swelling of expansive soils [11]. The projected cost of maintenance of structure constructed on swelling soil in China exceeded one billion per annum [12]. In Pakistan, many areas are also covered with expansive soils which have caused intense damages to various types of structures, such as cracking of single and double storied houses, lifting of floor slabs, and cracking of boundary walls as evident from Figure 1 [13].

Another issue related to the expansive soil also occurs during the process of deep excavations below the groundwater table. The groundwater and ground material rush out to the underground station due to piping failure. Recently, a study has been conducted on leakage probability of the underground structure system by [14].

As stated by Nelson and Miller and Puppala et al., the reason for this undesired behavior of the expansive is the limited current state of knowledge and practice, as soil mineralogy variations and unsaturated features of soil are not often considered $[15,16]$. Most of the problems in the field where expansive soils have been found arise from inappropriate soil characterization and inadequate soil swell potential evaluation. The main objective of this study is to assess precisely the geotechnical, mineralogical, and swelling behavior of local expansive soil for the subsequent utilization in design parameters. For this purpose, representative samples were collected from Karak, Kohat, and D.I. Khan areas in Khyber Pakhtoon Khwa (KPK) province, Pakistan, and assessed for the required characteristic.

\section{Literature Survey}

Expansive soil or clay is recognized as a potential hazard for civil engineering structures specifically when they are lightly or moderately loaded. The offensive activity of expansive soil may be contrived by many factors, but the major two of them are the presence of moisture and the percentage and type of fines particles in the soil. It is worth mentioning that whenever the moisture fluctuates in expansive soil, the volume change will take place. This volume change may be in the form of swelling or shrinkage; due to this behavior, such soils are also recognized as swell or shrink soils $[17,18]$. During the swelling period, the soil heaves, and when heaving is obstructed by engineering structure, then such soil exerts swell pressure on the lowermost structural element, i.e., foundation or slab. Many lightweight structures constructed over these soils can experience structural degradations, reduce proper functionality, and required additional costs for restoration. Accordingly, it is very crucial to measure accurately the geotechnical, mineralogical, and swell characteristics required for designing and 


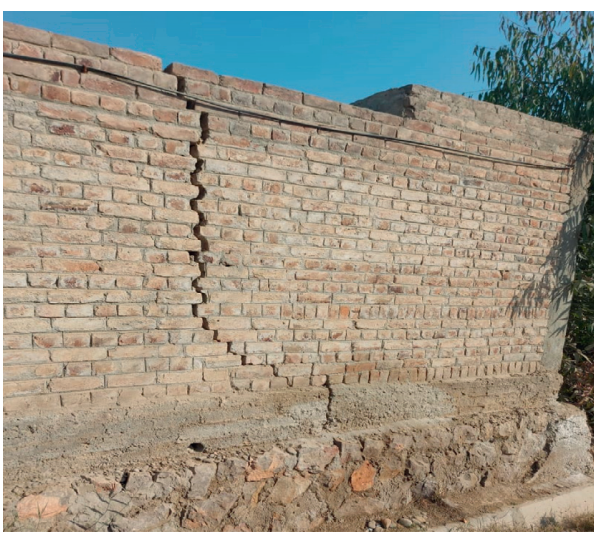

(a)

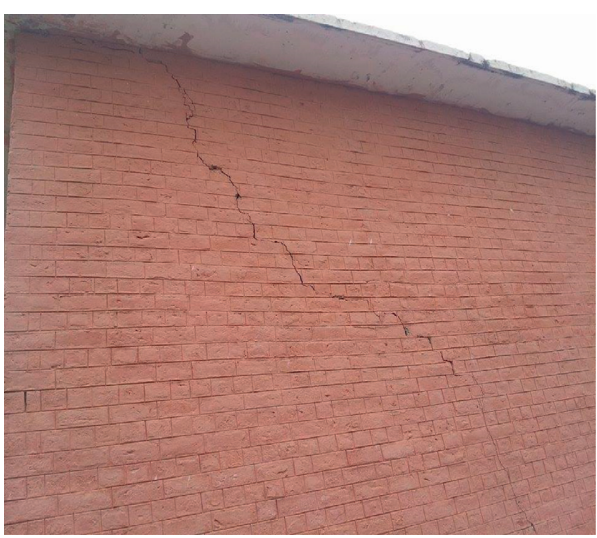

(b)

Figure 1: Boundary wall cracked due to the presence of expansive soil in the Kohat Cantt area.

implementing and controlling the soil heave. Compared with other soil, expansive soil possesses more plasticity due to the large water absorption capacity. Other factors influencing plasticity include particle size distribution, cation exchange capacity, and the presence of organic materials and salts $[19,20]$.

The swelling in the expansive soils is chiefly assessed by the presence of clayey minerals such as kaolinite, illite, and montmorillonite [21, 22]. The mineralogical characteristic is illustrated in Table 1 . The crystal of kaolinite is made of iteration layers, and every single layer consists of a silica sheet and an alumina sheet as mentioned in Figure 2. A layer of oxygen atoms is shared between them. The kaolin and halloysite clays are produced by the chemical weathering of alumina-silicates. A low silica-alumina ratio is required for the establishment of kaolin-like minerals.

The illite mineral is contained in cyclical alumina and silica sheets as illustrated in Figure 3(a). Illite swells and shrinks more than kaolinite due to its greater water absorption capacity. Montmorillonite minerals have the arrangement of the same layers as that of illite as mentioned in Figure 3(b).

The main difference in montmorillonite is that the isomorphous transposition takes place chiefly in the alumina sheet, with magnesium or iron replacing the dioctahedral minerals. Another commonly spread head clay mineral that belongs to the same class is bentonite, which is commonly constituted from volcanic residue through the process of weathering. Bentonite is recognized for its large swelling characteristic [24]. Based on the expansivity, the order of these minerals is montmorillonite $>$ kaolinite $>$ illite. Montmorillonite is composed of silica tetrahedrons and alumina octahedral joined through weak Van der Waal's forces. Bentonite has a liquid limit of $900 \%$ and a large specific surface area $\left(850 \mathrm{~g} / \mathrm{cm}^{2}\right)$ [25]. The montmorillonite carries a fixed negative charge over the surface, which is the function of isomorphous replacement of magnesium and $\mathrm{Fe}^{+}$[26], and two positive charges spread over the edges, which is the characteristic of the $\mathrm{pH}$ of the soil [27]. Kaolinite is the least expansive among the three clay minerals because of the presence of permanent $\mathrm{K}^{+}$ions. Illite has also a permanent $\mathrm{K}^{+}$ion among the interlayer spaces, which reduces the expansivity.

At the point when water connects with the clay minerals, then an intermolecular bond is formed due to the dipolar nature of water [28]. Water is absorbed on the surfaces of clay particles and also causes the hydration of ions. This process involved four different mechanisms at a time, namely, osmosis, dipole attraction, cation hydration, and hydrogen bonding. Nevertheless, the stress equilibrium is disturbed inside the clay-water mixture because of the $\mathrm{H}^{+}$ and $\mathrm{OH}^{-}$ions present in water and negative charge on the edges, which is responsible for the expansive movement $[29,30]$. This movement is often several times higher, and many techniques are used to estimate the resulting expansion. These methods include the consolidation approach, moisture measurement, and suction-based swell techniques [31].

The behavior of clay minerals is greatly impacted by the presence and profusion of dissolved ions. In the case of swelling clay, the constitution and molecular structure of clay have a greater affinity to attract and retain water molecules between the crystalline structure. As water, molecules have a dipole structure due to which an electrochemical attraction exists in them for the microscopic clay sheets. When high expansivity soils become hydrated, more water molecules are absorbed between the clay sheets, which causes an increase in the bulk volume or expansion. The interclay bond present in expansive soil weakens due to saturation, and the overall strength is reduced. However, when water present in the clay layers is relinquished by evapotranspiration or by gravity, the force then will cause a reduction in volume or shrink. The features as voids, desiccation, or cracks can be seen on the surface of expansive soil when shrinkage takes place. Expansive soil is chiefly recognized by conducting grain size analysis to ascertain the fine fraction in a specimen. Clay particles are less than two microns but the main difference between clays and silts depends on the parent source and particle shape. Silt particles (mostly comprising quartz particles) are products of physical erosion whereas clayey particles are produced by chemical weathering and are discriminated by their layer structure and organization [32]. 
TABLE 1: Mineralogical properties of fundamental clay minerals.

\begin{tabular}{|c|c|c|c|c|c|c|}
\hline Clay minerals & Bond intensity & $\begin{array}{c}\text { Isomorphous } \\
\text { substitution }\end{array}$ & $\begin{array}{c}\text { Shrink and } \\
\text { swell }\end{array}$ & $\begin{array}{c}\text { CEC } \\
(\mathrm{meq} / 100 \mathrm{~g})\end{array}$ & LL (\%) & $K(\mathrm{~m} / \mathrm{s})$ \\
\hline Kaolinite (1:1 clay mineral) & Hydrogen, strong & Low & Very low & $3-15$ & $30-75$ & $10^{-5} \sim 10^{-7}$ \\
\hline Illite $(2: 1$ clay mineral $)$ & K-ion, moderate & Moderate & Low & $10-40$ & $60-120$ & $10^{-6} \sim 10^{-8}$ \\
\hline $\begin{array}{l}\text { Montmorillonite } 2: 1 \text { coal } \\
\text { mineral }\end{array}$ & $\begin{array}{l}\text { Wonder wall, } \\
\text { weak }\end{array}$ & High & Very high & $29-150$ & Up to 900 & $10^{-7} \sim 10^{-9}$ \\
\hline
\end{tabular}

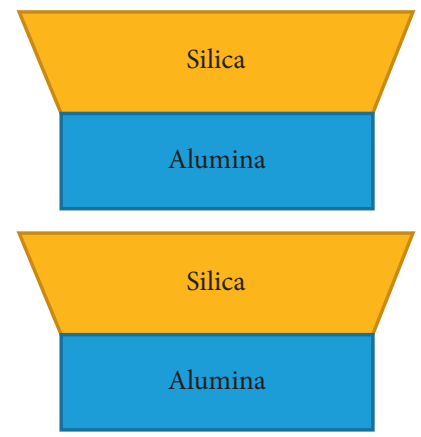

FIgURE 2: Structural arrangement of kaolinite crystal [23].

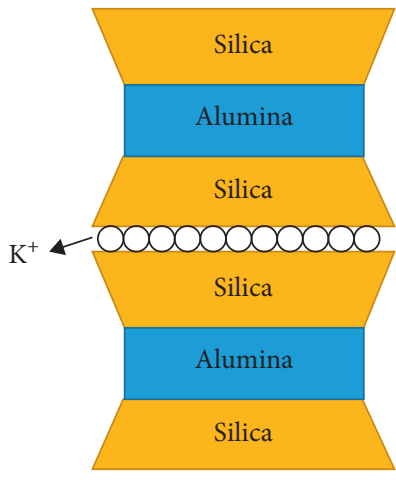

(a)

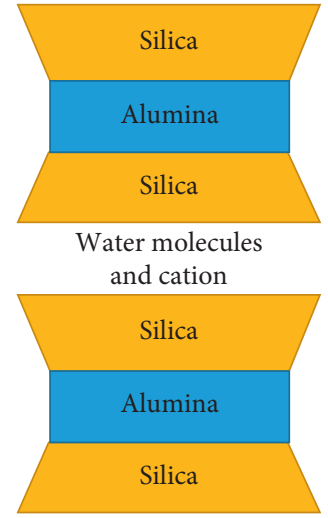

(b)

FIgURE 3: Arrangement of alumina and silica sheet in (a) illite and (b) montmorillonite [23].

Expansion and shrinkage are common features in the expansive soil because of the presence of clay minerals or chemically evoked changes. According to Bell and Culshaw, the shrink-swell potential of swelling soil is estimated by its initial moisture content, internal structure, void ratio, and overburdened stresses, as well as the type and amount of clay minerals in the soil [33]. The natural expansiveness of soil is often determined by the presence of specific minerals including montmorillonite, illite, nontronite, chlorite, and vermiculite. The greater the amount of these minerals in the soil, the higher will be the swell potential. However, the presence of some nonswelling minerals like quartz and calcite dilutes the expansivity of these soils. If more clay exists in the soil, there will be higher swelling and more water absorption capacity. The shrinkage happens when the moisture dries out through evaporation from these soils. Researchers have reported the safe expansion percentage equal to or smaller than $10 \%$ for most of the expansive clays [34].

To enumerate the soil shrinkage and swelling amount, the moisture content in the near-surface zone may be measured. Normally, most of the significant action happens in a shallow depth, not greater than three meters, although if the tree roots exist in the area, this depth may be protracted.

The characteristics of fine-grained clay-rich soils lead them to be capable enough to assimilate large amounts of water, which makes them heavy and sticky. On the other hand, these types of soils can become very hard when they dry, which leads them to shrink and have cracks on their surface. This procedure is known as the "shrinkage swell" behavior [1]. Swelling and shrinkage are not wholly reversible procedures [35]. Shrinkage results in cracks on the surface of the soil which cannot close up completely by rewetting the soil. Therefore, it makes the soil bulk out 
somehow. Besides, it can help the water to penetrate the soil more easily during the swelling process. It is worth mentioning that when substances like sediment enter the existing cracks in the soil, the soil is unable to get rid of them and go back to its previous situation; hence, it will increase the swelling pressure. Sometimes, the shrinkage or desiccation cracks may be filled with sediment which leads to the incompatibility of the soil. One of the primary problems with the expansive soil is that deformations are considerably greater than the predicted ones, which are derived from the classical elastic and plastic theory.

Numerous researchers have highlighted the damages associated with expansive soil for instance; the cyclic swell and shrink in the expansive Regina soil have impaired engineering structure such as transportation system [36], residential, commercial, and industrial facilities [37], and water supply lines and sewage collection facilities [38]. Furthermore, damages to engineering facilities are manifested in the form of nonuniform heave in roadways and sidewalks, the inclined crack in slab-on-grade, basements and brick walls, fatigue, and failures in underground storage tanks and buried pipelines. The associated repair and rehabilitation cost for these structures is enormous.

\section{Material Collection and Assessments}

For this experimental study, material (expansive soil) was collected from three sites, i.e., Karak, Kohat, and D.I, Khan in the province of KPK, Pakistan. The exact locations of these sites on the Google map along with their coordinates are shown in Figure 4.

The quantity of expansive soils collected from each site was about 0.5 tons. Samples were collected after removing the top weathered materials ( 1.5 feet down) from natural surface level (NSL) up to six feet depths. The representative samples were properly packed to the Geotechnical Laboratory of CECOS University Peshawar, Pakistan. Samples were oven-dried $\left(105^{\circ} \mathrm{C}\right.$ for 24 hours) to find the natural moisture content. For grinding the hard and dry chunks of expansive soil, the ball-grinding technique was utilized, adapted from Tang et al. [39] before performing the basic and specialized geotechnical testing.

To assess the geotechnical, mineralogical, and swelling behavior, extensive experimental work was conducted according to the ASTM and other available testing methodology as highlighted hereinafter.

(i) The gravimetric moisture content was estimated as a percentage of the dry weight of soil, at a temperature of $105^{\circ} \mathrm{C}$ according to ASTM D-2216 standard test methodology

(ii) The grain size distribution (GSD) of the expansive soil was comprised of both hydrometers (for finegrain) and sieve analysis (for coarse fraction) following the ASTM D-422

(iii) The compaction test of each soil sample was conducted following ASTM D-698 (a) to obtain the dry density relationship of the expansive soils (iv) The specific gravity was found by the Pycnometer methodology according to ASTM D-5550-06

(v) The swelling behavior was assessed in terms of swell potential (S) and swell pressure (Sp) following the ASTM D-4546 test procedure

(vi) The scanning electron microscopy (SEM) strategy as per ASTM E-986-04 was utilized to assess the surface morphology (images) of the expansive soils

(vii) The mineralogical investigation of Karak, Kohat, and D.I. Khan soils was carried out through X-ray diffraction (XRD) analysis utilizing a JDX-3532 diffractometer made by JEOL, Japan

\section{Experimental Findings and Discussions}

For proper characterization and classification of expansive soils, basic geotechnical tests were conducted comprising consistency limits, specific gravity, wet sieve analysis, sedimentation analysis, and standard proctor tests. The mineralogy and morphology were studied through SEM and XRD analysis while the swelling behavior and deformation were assessed with the help of conventional odometer tests. The findings of experimental work are presented in the following section with a comprehensive discussion of the results.

4.1. Consistency and Specific Gravity Results. The results of the consistency limits and specific gravity of the tested soils are presented in Table 2. The Karak soil (S1) exhibits the highest plasticity value while the D.I. Khan soil (S2) showed the least plasticity. Based on the consistency limits values, the Karak expansive soil is more plastic than Kohat and D.I. Khan expansive soils. The specific gravity of the Karak soil is also greater than Kohat and D.I. Khan Soil.

4.2. Sieve and Hydrometer Analysis. For plotting the grain size distribution (GSD) curve for the collected samples, both sieve and hydrometer analysis tests were conducted. The gradation curves obtained from the combination of sieve (for course fraction) and hydrometer (for fine fraction) for Karak, D.I. Khan, and Kohat expansive soils are presented in Figures 5(a)-5(c), respectively.

The various percentages of sand, silt, and clay as estimated from the gradation curves of these soils are also listed in Table 3. From the gradation curve, the Karak expansive soil showed the highest percentage of clay while the D.I. Khan soil has the least percentage of clay. Additionally, the D.I. Khan soil contains more silt than Kohat and Karak soil.

4.3. Compaction Tests Results. Standard proctor tests were performed on the collected specimens of Karak, D.I. Khan, and Kohat expansive soils, and their results have appeared in Figure 6.

The maximum dry densities (MDD) and percent optimum moisture content (OMC) were determined from the peaks of the compaction curves. A maximum dry density of $1.9 \mathrm{~g} / \mathrm{cm}^{3}, 1.8 \mathrm{~g} / \mathrm{cm}^{3}$, and $1.72 \mathrm{~g} / \mathrm{cm}^{3}$ can be achieved at a 


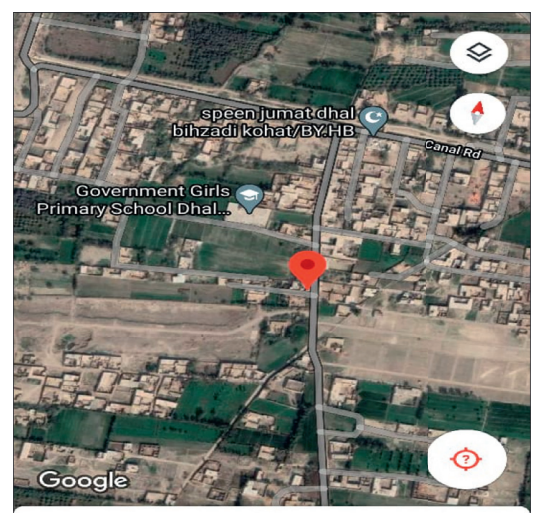

$33^{\circ} 33^{\prime} 10.8^{\prime \prime} \mathrm{N} 71^{\circ} 25^{\prime} 44.4^{\prime \prime} \mathrm{E}$

(a)

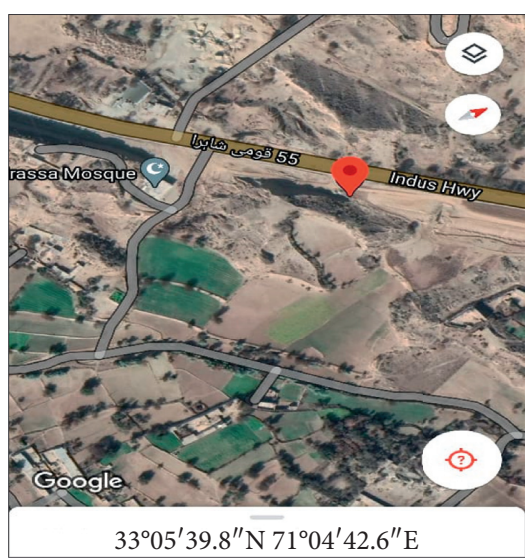

(b)

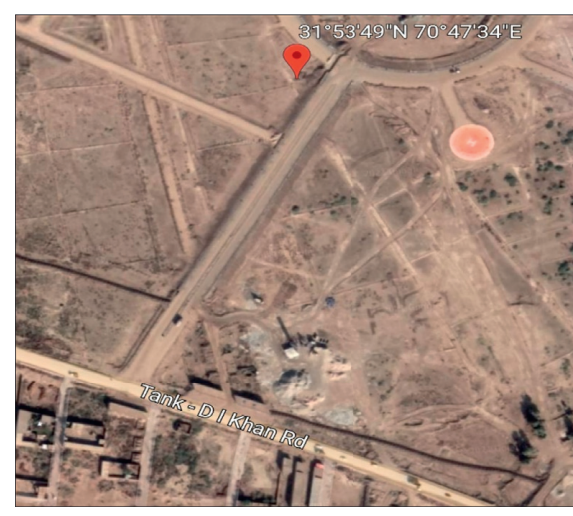

(c)

Figure 4: The coordinates of Kohat (a), Karak (b), and D.I. Khan (c) expansive soil.

TAble 2: Some basic properties of tested soils. Liquid limit: LL; plastic limit: PL; plasticity index: PI; specific gravity: $G_{s}$.

\begin{tabular}{|c|c|c|c|c|c|}
\hline Locations & Designation & LL (\%) & PL (\%) & PI (\%) & $G_{s}$ \\
\hline Karak & S1 & 60 & 23 & 37 & 2.7 \\
\hline D.I Khan & S2 & 34 & 11 & 23 & 2.60 \\
\hline Kohat & S3 & 50.5 & 20 & 30.5 & 2.68 \\
\hline
\end{tabular}

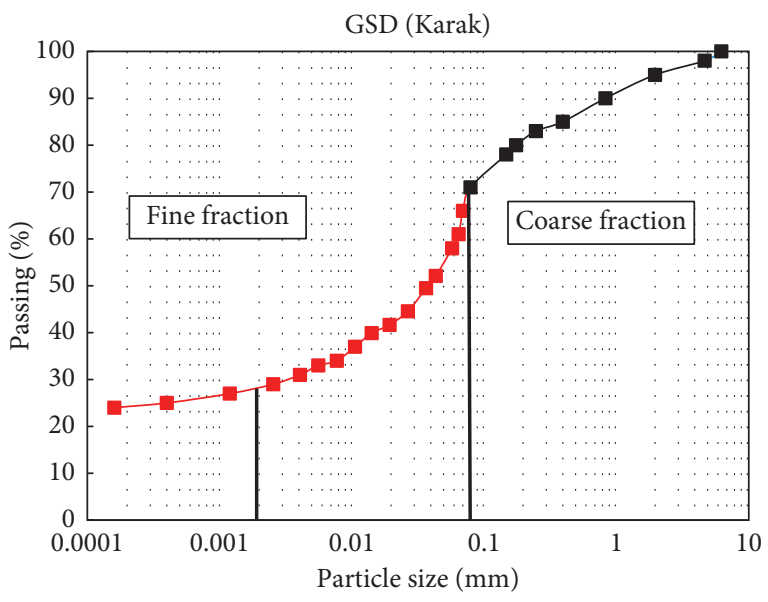

(a)

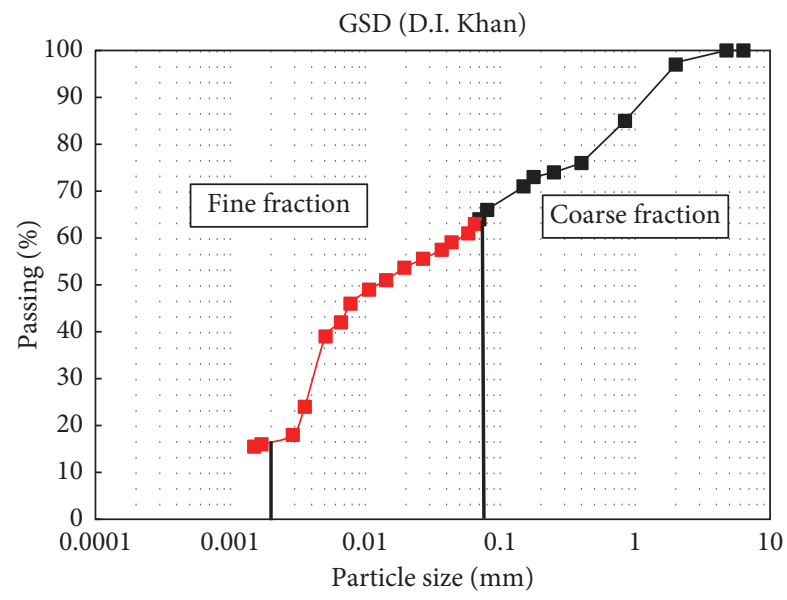

(b)

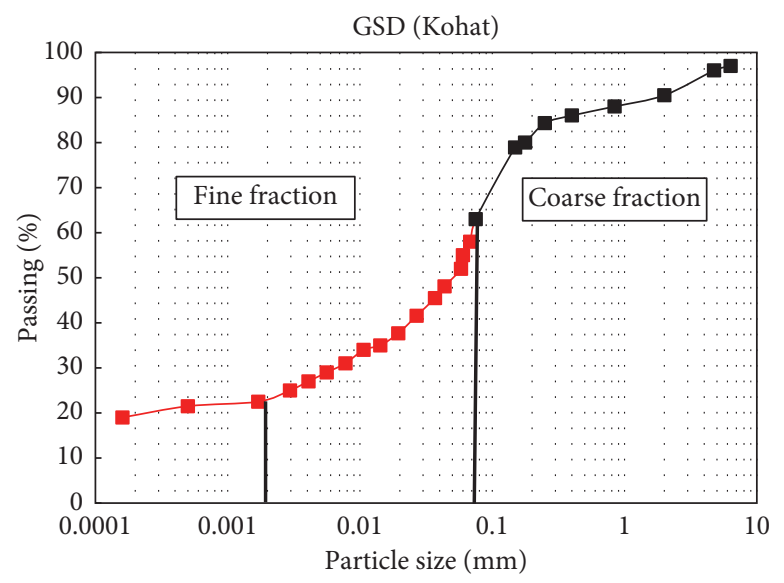

(c)

Figure 5: The grain size distribution curves of Karak (a), D.I. Khan (b), and Kohat (c) expansive soils. 
TABLE 3: Summary of the gradation tests showing the percentages of coarse and fine fractions.

\begin{tabular}{|c|c|c|c|c|}
\hline \multirow{3}{*}{ Soil } & \multicolumn{4}{|c|}{ Gradation } \\
\hline & \multicolumn{2}{|c|}{ Coarse fraction } & \multicolumn{2}{|c|}{ Fine fraction } \\
\hline & Gravel (\%) & Sand $(\%)$ & Silt (\%) & Clay (\%) \\
\hline Karak & 0.0 & 28 & 44 & 28 \\
\hline D.I Khan & 0.0 & 37 & 46 & 17 \\
\hline Kohat & 0.0 & 36 & 41 & 23 \\
\hline
\end{tabular}

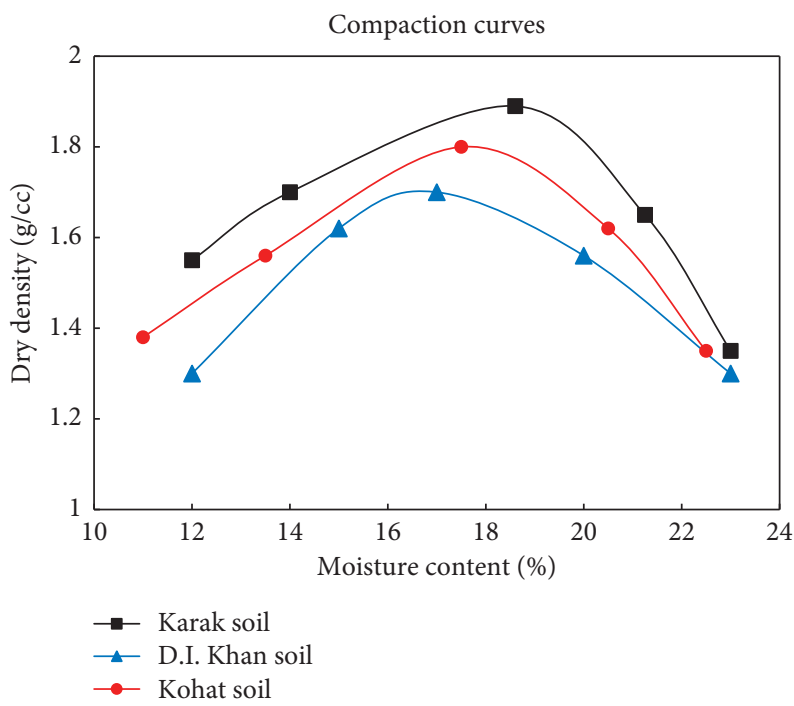

FIGURE 6: Compaction curves showing the dry density and moisture fluctuation of Karak, Kohat, and D.I. Khan expansive soils.

moisture content of $18.6 \%, 17.5 \%$, and $17 \%$ in Karak, D.I. Khan, and Kohat expansive soil, respectively. The difference in the optimum moisture content (OMC) of these soils is due to the difference in their consistency limits and the percentage of fines present. As the liquid limit and plasticity index of the Kohat and D.I. Khan soils are less than the Karak soil due to which the maximum dry unit weight was achieved at competitively low moisture content, similarly, the percentage of fines in these sites was also less than the Karak soil, and hence less amount of water is required for saturating the surface area of these fines.

4.4. Basic Classification. Based on plasticity index values, all the tested soil samples were classified. For this purpose, the designated groups according to the Unified Soil Classification System (USCS) and their plasticity index are mentioned against each sample in Table 4. Additionally, all the samples were also classified based on their expansivity using the Chen criteria as shown in the same table. The Karak and Kohat soil is classified as $\mathrm{CH}$ soil, i.e., clay with a high liquid limit or fat clay or expansive soil of high expansivity, while the D.I. Khan soil is classified as CL soil, i.e., clay with a low liquid limit or medium expansive soil due to its low plasticity index as appeared in Table 4.

4.5. SEM Characterization. The SEM of Karak, D.I. Khan, and Kohat and D.I. Khan's expansive soil is mentioned in Figures 7(a)-7(c). The morphology of Karak expansive soil showed nonregular agglomerates composed of comparatively flat sheets overlapped over each other. The soil particle showed large flat layers or leaves of clayey minerals randomly overlapped over each other as shown in Figure 7(a). This SEM image resembles scattered leaves of kaolinite and illite structures.

In D.I. Khan expansive soil, the presence of silt and sand clusters was noticed as demonstrated in Figure 7(b). The presence of sand and silt reduces the potential swelling and shrinkage in this soil.

The SEM image of Kohat soil showed damaged large surface montmorillonite mineral species as appeared in Figure 7(c). Due to sample disturbance, none of the SEM images showed a proper stack or booklet structure.

4.6. XRD Analysis. While performing qualitative analysis for the Karak expansive soil, the sample showed various percentages of clayey and nonclayey minerals species as given in Figure 8. For assessing the swelling behavior of Karak soil, the minerals, which are responsible for the swell potential, were selected only in this investigation. These minerals include montmorillonite, nontronite, kaolinite, palygorskite, and illite. During the quantitative analysis, the relative percentages $(\mathrm{Rp})$ of these minerals were determined which are mentioned against each mineral in Figure 8 . The mineral palygorskite has the highest percentage $(\mathrm{Rp}=20 \%)$, and nontronite has the least percentage $(\mathrm{Rp}=6.4)$ among the clayey minerals. Furthermore, nonclayey minerals like 
TABLE 4: Initial and expansion-based classification of the selected expansive soils.

\begin{tabular}{lcccc}
\hline Soil sample & Pl (\%) & USCS & Expansivity & Chen criteria \\
\hline Karak & 37 & CH & High & $\begin{array}{c}\text { PI }=10-15 \\
\text { Low }\end{array}$ \\
\hline D.I Khan & 23 & CL & Medium & $\begin{array}{c}\text { PI }=15-28 \\
\text { Medium }\end{array}$ \\
\hline Kohat & 30.5 & CH & High & PI $=28-41$ \\
High
\end{tabular}

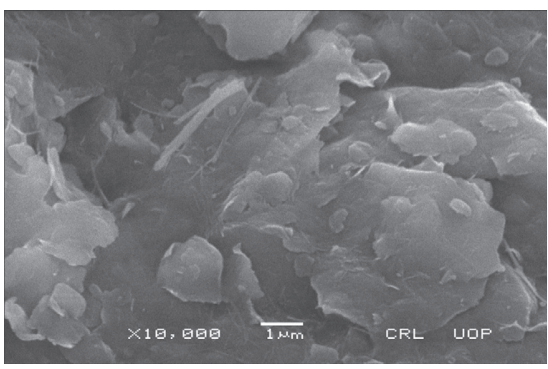

(a)

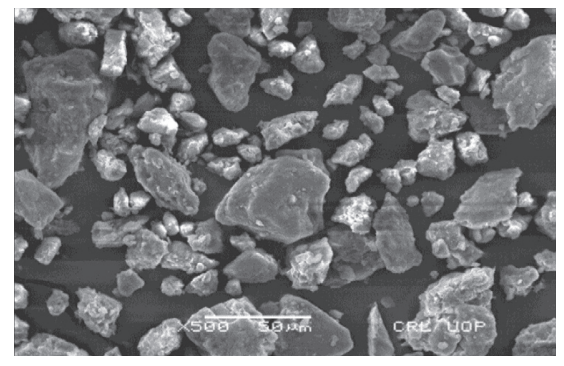

(b)

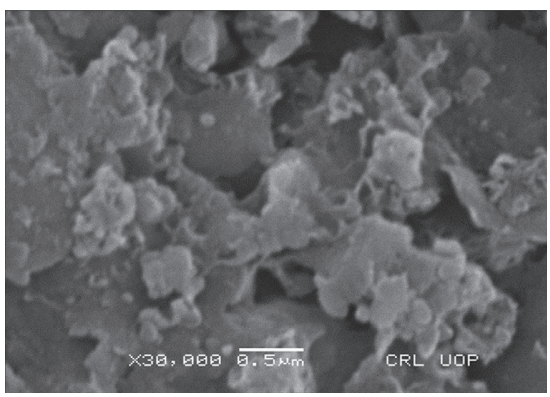

(c)

Figure 7: (a) The large surface miners overlapped randomly in Karak soil. (b) SEM of D.I. Khan expansive soil showing the cluster of silt and sand. (c) Large broken surfaces of montmorillonite mineral species in Kohat soil.

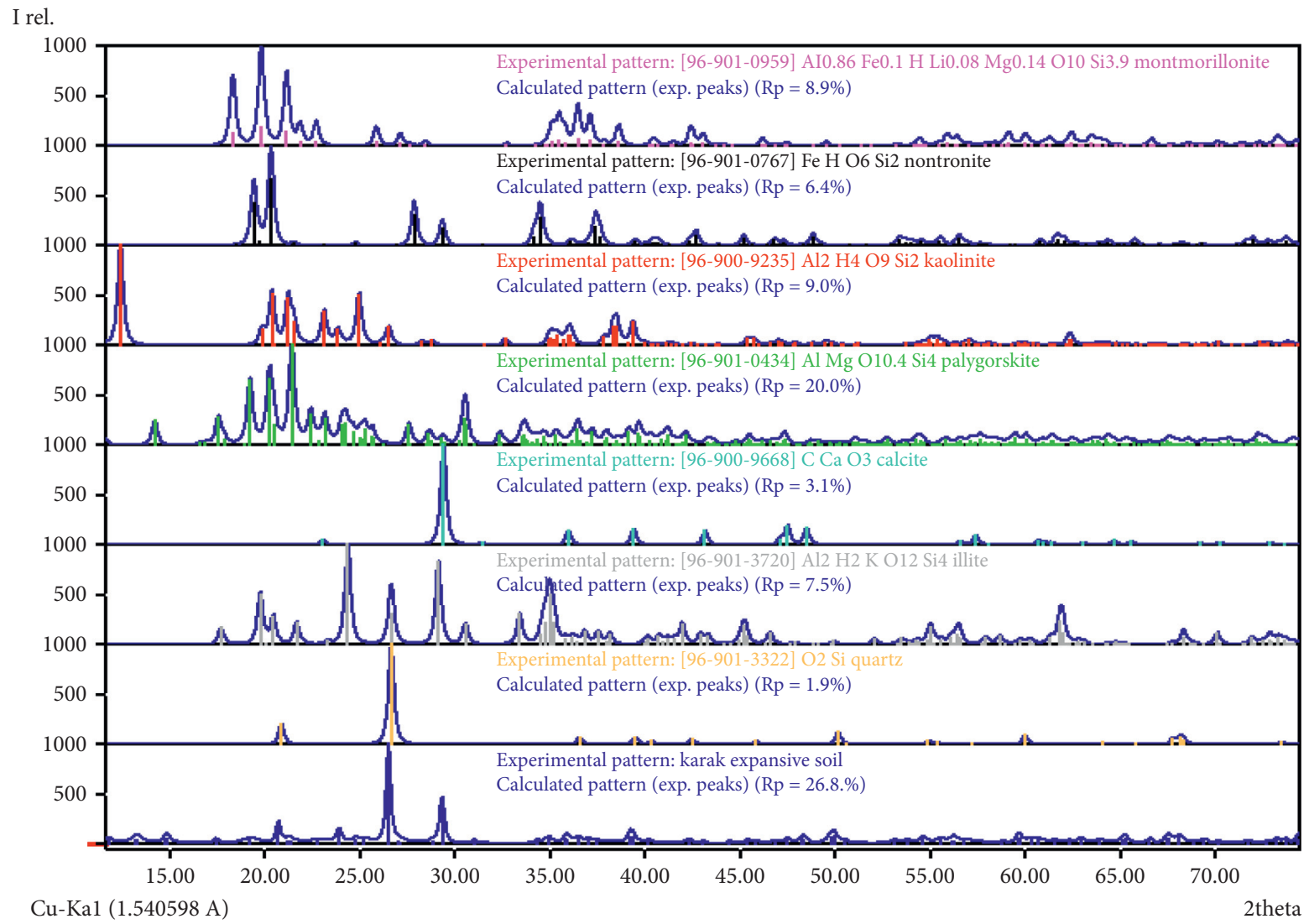

Figure 8: X-ray diffractogram of Karak expansive soil generated in match. 


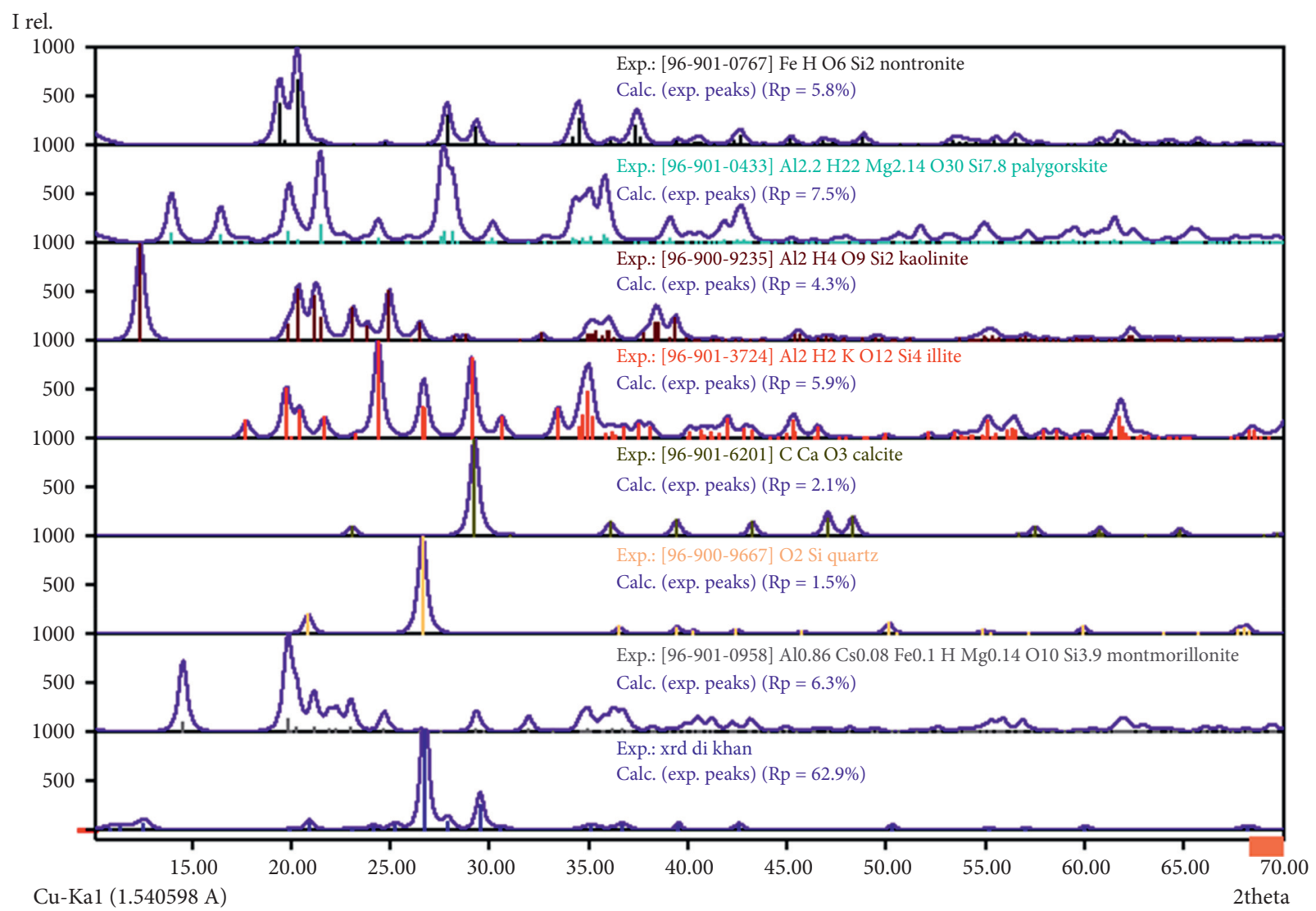

FIGURE 9: X-ray diffractogram of D.I. Khan expansive soil produced in match.

Table 5: Percent Rp values of minerals identified in Karak, Kohat, and D.I. Khan soils.

\begin{tabular}{lccc}
\hline Minerals species & $\begin{array}{c}\text { Karak } \\
\text { Experimental peak (Rp \%) }\end{array}$ & $\begin{array}{c}\text { Kohat } \\
\text { Experimental peak (Rp \%) }\end{array}$ & $\begin{array}{c}\text { D.I. Khan } \\
\text { Experimental peak (Rp \%) }\end{array}$ \\
\hline Montmorillonite & 8.9 & 7.0 & 6.3 \\
Nontronite & 6.4 & 1.0 & 5.8 \\
Kaolinite & 9.0 & 2.9 & 4.3 \\
Illite & 7.5 & 1.7 & 5.9 \\
Palygorskite & 20.0 & 3.7 & 7.5 \\
Quartz & 1.9 & 0.4 & 1.5 \\
Calcite & 3.1 & 0.4 & 1.5 \\
\hline
\end{tabular}

quartz and calcite were also identified in Karak soil. The relative percentages of these minerals are $1.9 \%$ and $3.1 \%$, respectively. The aggregated $\mathrm{Rp}$ values of quartz and calcite (nonswelling minerals) were 5.0 percent.

The diffractogram of D.I. Khan soil as demonstrated in Figure 9 revealed that the clay mineral assemblage in the profiles contains both smectite and kaolinite. The expandable clay mineral, smectite, is the dominant mineral component present in this soil. The Rp of quartz and calcite were $1.5 \%$ and $2.1 \%$, respectively. The maximum $\mathrm{Rp}$ of $7.5 \%$ was shown by palygorskite among the swelling minerals. The minimum Rp was $4.3 \%$ for clayey minerals (kaolinite). The $\mathrm{Rp}$ value for other minerals is shown in Figure 9 and has been summarized in Table 5 .

Kaolinite and illite minerals were also present in Kohat soil showing the clayey nature of this soil. The Rp values of montmorillonite, palygorskite, kaolinite, illite, and nontronite are $7.0 \%, 3.7 \%, 2.9 \% 1.7 \%$, and $1.0 \%$, respectively, as mentioned in Figure 10. Quartz and calcite were present in the very least amount, and their combined $\mathrm{Rp}$ was $0.8 \%$, which is comparatively less than the Karak soil and D.I. Khan soil. The quartz and calcite content revealed by XRD accounts for the silt size fraction as also observed in the grain size distribution (GSD) curve. The summary of Rp percentages of selected minerals of all three sites is given in Table 5 .

4.7. Swell Behavior and Deformation. The swelling behavior of the selected expansive soils was determined in terms of swell potential (S) and swelling pressure (Sp). But for deformation, only one-dimensional deformation was considered in the analysis. 


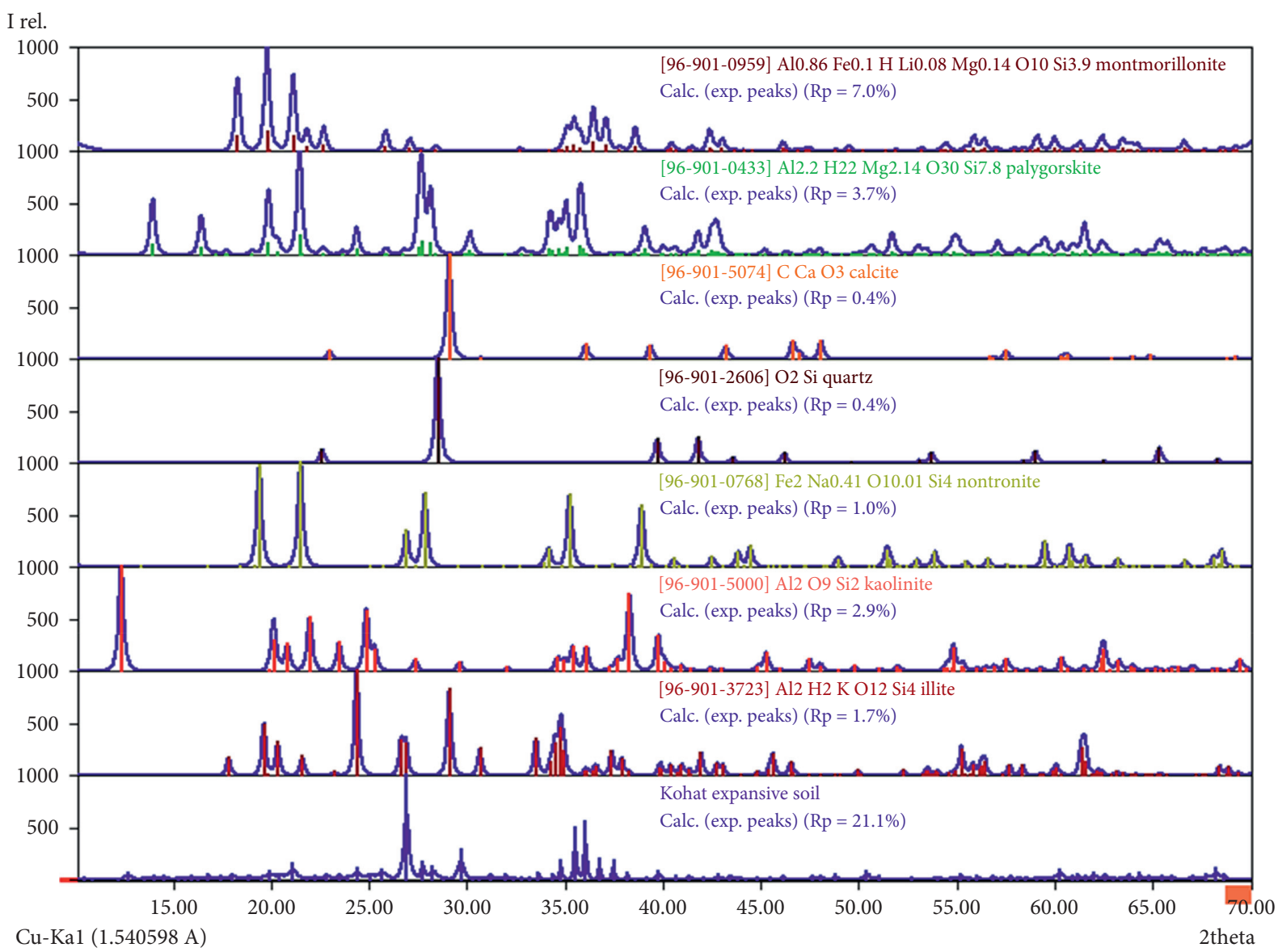

FIGURE 10: X-rays diffractogram of Kohat expansive soil generated in match.

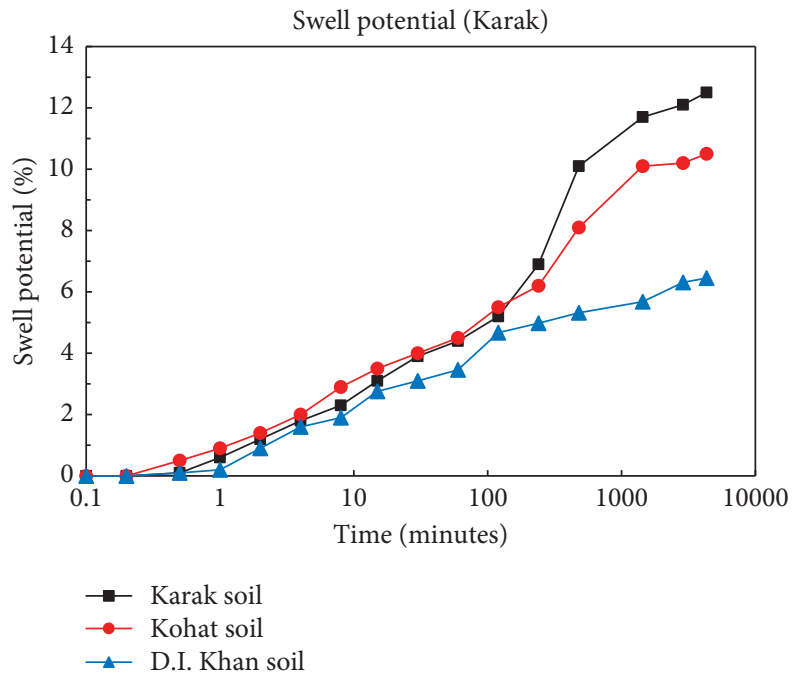

Figure 11: Swell potential curves of the selected sites showing percent swell.

All the samples were tested for swell potential in the conventional odometer apparatus under a seating load of one $\mathrm{kPa}$. The maximum swell potential was $12.5 \%, 10.5 \%$, and $6.45 \%$ for Karak, Kohat, and D.I. Khan soil, respectively. In the initial stages, the change in swelling was limited and becomes much pronounced in the later stages as shown in Figure 11.

From this expanded stage, the samples were subjected to incremental load in the odometer apparatus to compress it again to the original height. The final deformation after 


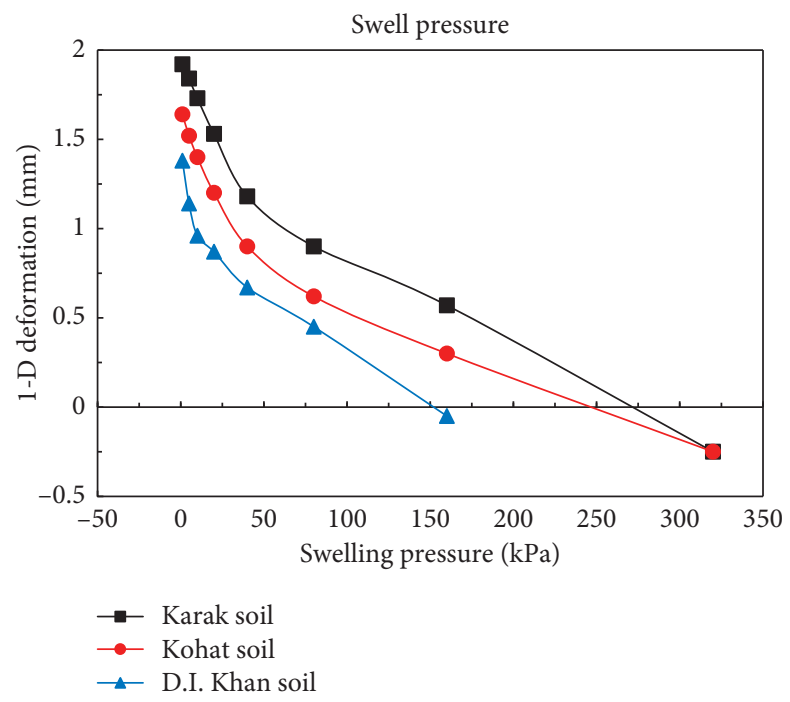

FIGURE 12: Swell pressure and one-dimensional strains for the selected soils.

TABLE 6: Summary of swell potential (S), swell pressure (Sp), and 1D deformation.

\begin{tabular}{lcccc}
\hline Locations & Samples designation & Deformation $(\mathrm{mm})$ & Swell potential $(\%)$ & Swell pressure $(\mathrm{kPa})$ \\
\hline Karak & $\mathrm{S} 1$ & 1.92 & 12.5 & 280 \\
D.I. Khan & $\mathrm{S} 4$ & 1.38 & 6.45 & 150 \\
Kohat & $\mathrm{S} 8$ & 1.64 & 10.5 & 245 \\
\hline
\end{tabular}

swelling was $1.92 \mathrm{~mm}, 1.64 \mathrm{~mm}$, and $1.38 \mathrm{~mm}$ for Karak, Kohat, and D.I. Khan soils, respectively. The maximum load backpressure for these soils was $320 \mathrm{kPa}, 320 \mathrm{kPa}$, and $160 \mathrm{kPa}$, respectively, in accordance with ASTM D-4546 methodology as mentioned in Figure 12. These loads were then corrected for zero deformation to obtain the swell pressure. The corrected swell pressures are $280 \mathrm{kPa}, 245 \mathrm{kPa}$, and $150 \mathrm{kPa}$ for Karak, Kohat, and D.I Khan soils, respectively. The summary of swell potential (S), swell pressure $(\mathrm{Sp})$, and 1-D deformation is demonstrated in Table 6.

\section{Summary and Conclusions}

An experimental study has been conducted to investigate the geotechnical, mineralogical, and swelling behavior of local expansive soils. For this reason, disturbed samples were collected from three sites of expansive soils. Following are the main conclusions that can be drawn from this investigation.

(i) Basic engineering properties and classification of the three expansive soils showed that Karak soil has high plasticity index and swell characteristics than Kohat and D.I Khan soils.

(ii) Out of the three sites, Karak soil contains a higher percentage of clay as distinguished from the GSD curves. Additionally, the percentage of silt in D.I. Khan soil is greater than Kohat and Karak soil, which makes it medium expansive soil.

(iii) It is worth mentioning that the overall swell behavior cannot be anticipated from the percent Rp estimation of montmorillonite only. More precision in the results of swell conduct can be accomplished if the proportions of clayey and nonclayey mineral species are considered.

(iv) The presence of a small amount of montmorillonite minerals in the soil can make it expansive and become problematic for lightly loaded structures constructed on it. Similarly, a slight increase of montmorillonite in expansive soil can significantly increase the swell potential of expansive soils while the swell characteristic is minimized by the presence of quartz and calcite minerals.

(v) The swell pressure and swell potential of an expansive soil increase with the increase in the clay fraction and decrease with the presence of silt and sand fraction.

(vi) As D.I. Khan soil contains more silt and sand fraction and has the low swelling characteristic, no potential damages occur in structures constructed in this area.

(vii) Kohat and Karak soils are highly expansive and major distresses can happen in lightly loaded structures constructed in these areas. Hence, some special construction techniques are required to mitigate the expected damages due to swelling.

(viii) The estimated parameters of swell pressure and swell potential are based on the testing of selected samples from the mentioned locations and can be used as a reference value in the design protocol. However, more accuracy and precision can be 
achieved if further testing is also carried out for a specific project in hand.

\section{Recommendations}

(i) Both swelling and shrinkage are the characteristics of expansive soils. However, only the swelling part in terms of swell pressure and swell potential is assessed in the current investigation. Therefore, further study needs to be carried out in this domain, where linear or volumetric shrinkage should be considered the major concern of the research

(ii) Based on the current investigation, it is recommended to stabilize the foundation soils by adding some nonswelling (coarse sand) locally available in Karak and Kohat areas to protect the residential buildings constructed in the future. This can be an economical solution for small projects

(iii) However, in the case of pavement for transportation and pipeline installations for gas and water supply facilities, it is recommended to change the proposed route/alignment if it passes through some expansive soil deposit, as this stabilizationtechnique will not be useful due to the enormous increase in the overall expenses utilized.

\section{Data Availability}

The background data used for supporting the findings of this investigation can be acquired from the corresponding authors upon request.

\section{Conflicts of Interest}

The authors of this research article have no conflicts of interest regarding its publication.

\section{References}

[1] B. Kalantari, "Foundations on expansive soils: a review," Research Journal of Applied Sciences, Engineering, and Technology, vol. 4, no. 18, pp. 3231-3237, 2012.

[2] V. N. S. Murphy, Soil Mechanics and Foundation Engineering, CBS Publishers and Distributors Pvt. Ltd., New Delhi, India, 2010.

[3] R. E. Grim, Clay Mineralogy, McGraw-Hill Book Company, New York, PA, USA, 2nd edition, 1968.

[4] A. J. Puppala, K. Punthutaecha, and S. K. Vanapalli, "Soilwater characteristic curves of stabilized expansive soils," Journal of Geotechnical and Geoenvironmental Engineering, vol. 132 , no. 6 , pp. 736-751, 2006.

[5] F. H. Chen, Foundations on Expansive Soils, Elsevier, Amsterdam, Netherlands, 2012.

[6] B. Zamin, H. Nasir, K. Mehmood, and Q. Iqbal, "Field-obtained soil-water characteristic curves of KPK expansive soil and their prediction correlations," Advances in Civil Engineering, vol. 2020, Article ID 4039134, 13 pages, 2020.

[7] A. Puppala, L. Hoyos, C. Viyanant, and C. Musenda, "Fiber and fly ash stabilization methods to treat soft expansive soils," in Proceedings of the Soft Ground Technology, Noordwijkerhout, The Netherlands, June 2000.
[8] M. M. Zumrawi, "Construction problems of light structures founded on expansive soils in Sudan," International Journal of Science and Research, vol. 4, no. 8, pp. 896-902, 2015.

[9] A. Al-Swaidani, I. Hammoud, and A. Meziab, "Effect of adding natural pozzolana on geotechnical properties of limestabilized clayey soil," Journal of Rock Mechanics and Geotechnical Engineering, vol. 8, no. 5, pp. 714-725, 2016.

[10] Ö. Çimen, S. N. Keskin, and H. Yıldırım, "Prediction of swelling potential and pressure in compacted clay," Arabian Journal for Science and Engineering, vol. 37, no. 6, pp. 15351546, 2012.

[11] E. R. Tuncer, "Geotechnical properties of some selected Irbid soils," Report No. 14/87, Jordan University of Science and Technology, Irbid, Jordan, 1990.

[12] B. Shi, H. Jiang, Z. Liu, and H. Y. Fang, "Engineering geological characteristics of expansive soils in China," Engineering Geology, vol. 67, no. 1-2, pp. 63-71, 2002.

[13] K. Farooq, "Engineering characteristics of expansive soils in Pakistan," Doctoral Dissertation, M. Sc. thesis, University of Engineering and Technology, Lahore, Pakistan, 1996.

[14] P. Castaldo, F. Jalayer, and B. Palazzo, "Probabilistic assessment of groundwater leakage in diaphragm wall joints for deep excavations," Tunnelling and Underground Space Technology, vol. 71, pp. 531-543, 2018.

[15] J. Nelson and D. J. Miller, Expansive Soils: Problems and Practice in Foundation and Pavement Engineering, John Wiley \& Sons, Hoboken, NJ, USA, 1997.

[16] A. J. Puppala, T. Manosuthkij, S. Nazarian, L. R. Hoyos, and B. Chittoori, "In situ matric suction and moisture content measurements in expansive clay during seasonal fluctuations," Geotechnical Testing Journal, vol. 35, no. 1, pp. 74-82, 2012.

[17] L. Jones, V. Banks, and I. Jefferson, Chapter 8 Swelling and SS, Geological Society, London, Engineering Geology Special Publications, London, UK, 2020.

[18] S. Liu, Y. Lu, L. Weng, and F. Bai, "Field study of treatment for expansive soil/rock channel slope with soilbags," Geotextiles and Geomembranes, vol. 43, no. 4, pp. 283-292, 2015.

[19] R. M. Schmitz, C. Schroeder, and R. Charlier, "Chemo-mechanical interactions in clay: a correlation between clay mineralogy and Atterberg limits," Applied Clay Science, vol. 26, no. 1-4, pp. 351-358, 2004.

[20] F. Bergaya and G. Lagaly, "General introduction," in Developments in Clay Science, Elsevier, Amsterdam, Netherlands, 2013.

[21] A. Aqeel, "Investigation of expansive soils in Obhor Sabkha, Jeddah-Saudi Arabia," Arabian Journal of Geosciences, vol. 9, no. 4, p. 314, 2016.

[22] B. A. Hakami and E. Seif, "Expansive potentiality of Sabkha soils of Rabigh lagoon, Saudi Arabia: a case study," Arabian Journal of Geosciences, vol. 12, no. 4, p. 107, 2019.

[23] K. Tehrani, "Developing a new-instrumented soil column to study climate-induced ground movement in expansive soil," Doctoral Dissertation, Queensland University of Technology, Brisbane, Australia, 2016.

[24] F. E. Jalal, Y. Xu, B. Jamhiri, and S. A. Memon, "On the recent trends in expansive soil stabilization using calcium-based stabilizer materials (CSMs): a comprehensive review," $A d$ vances in Materials Science and Engineering, vol. 2020, Article ID 1510969, 23 pages, 2020.

[25] C. C. Ikeagwuani and D. C. Nwonu, "Emerging trends in expansive soil stabilisation: a review," Journal of Rock Mechanics and Geotechnical Engineering, vol. 11, no. 2, pp. 423-440, 2019. 
[26] I. M. Idriss and R. W. Boulanger, "SPT-based liquefaction triggering procedures," Report No. UCD/CGM1002, Center for Geotechnical Modeling, Department of Civil and Environmental Engineering, University of California, Davis, CA, USA, 2010.

[27] H. Elbadry, "Simplified reliable prediction method for determining the volume change of expansive soils based on simply physical tests," HBRC Journal, vol. 13, no. 3, pp. 353-360, 2017.

[28] J. D. Nelson, K. C. Chao, D. D. Overton, and E. J. Nelson, Foundation Engineering for Expansive Soils, Wiley, Hoboken, NY, USA, 2015.

[29] M. Labib and A. Nashed, "GIS and geotechnical mapping of expansive soil in Toshka region," Ain Shams Engineering Journal, vol. 4, no. 3, pp. 423-433, 2013.

[30] H. Akgün, A. Günal Türkmenoğlu, A. Arslan Kelam, K. Yousefi-Bavil, G. Öner, and M. K. Koçkar, “Assessment of the effect of mineralogy on the geotechnical parameters of clayey soils: a case study for the Orta County, Çankırı, Turkey," Applied Clay Science, vol. 164, pp. 44-53, 2018.

[31] J. K. Mitchell and K. Soga, Fundamentals of Soil Behavior, John Wiley \& Sons, Hoboken, NY, USA, 2005.

[32] P. T. Bobrowsky and B. Marker, Encyclopedia of Engineering Geology, Springer, New York, NY, USA, 2018.

[33] F. G. Bell and M. G. Culshaw, "Problems soils: a review from a British perspective," in Proceedings of the Problematic Soils, Thomas Telford Publishing, Nottingham, UK, November 2001.

[34] L. D. Jones and I. Jefferson, Expansive Soils, ICE Publishing, London, UK, 2012.

[35] R. D. Holtz, W. D. Kovacs, and T. C. Sheahan, An Introduction to Geotechnical Engineering, Prentice-Hall, Hoboken, NY, USA, 1981.

[36] A. J. Kelly, E. K. Sauer, S. L. Barbour, E. A. Christiansen, and R. A. Widger, "Deformation of the deer creek bridge by an active landslide in clay shale," Canadian Geotechnical Journal, vol. 32, no. 4, pp. 701-724, 1995.

[37] M. Ito and S. Azam, "Engineering characteristics of a glaciolacustrine clay deposit in a semi-arid climate," Bulletin of Engineering Geology and the Environment, vol. 68, no. 4, pp. 551-557, 2009.

[38] Y. Hu and D. W. Hubble, "Failure conditions of asbestos cement water mains in Regina," in Proceedings of the 1st CSCE Specialty Conference on Infrastructure Technologies, Management and Policy, pp. 2-4, Toronto, Canada, August 2005.

[39] A. Tang, L. Su, and C. Li, "Effect of dry grinding on the physicochemical properties of silica materials prepared from kaolin residue," Powder Technology, vol. 218, pp. 86-89, 2012. 